\title{
Newborn growth parameters in babies of working and nonworking women: A comparative study
}

\author{
*G R Sunilkumar ${ }^{1}$, K Shwetha $^{2}$, V Pooja ${ }^{3}$ \\ Sri Lanka Journal of Child Health, 2016; 45(4): 276-278
}

\begin{abstract}
Objective: To compare neonatal growth parameters in babies of working and non-working women.
\end{abstract}

Method: This is a hospital based comparative study conducted on pregnant women between 18-35 years of age. Thirty working mothers and 30 nonworking mothers were selected during their antenatal visit to the hospital. The newborn growth parameters recorded after birth were statistically analysed.

Results: In working women mean birth weight, length and head circumference were $2.84 \mathrm{~kg}, 51.8 \mathrm{~cm}$ and $34.3 \mathrm{~cm}$ and in non-working women $2.81 \mathrm{~kg}$ (p $>0.05), 48.6 \mathrm{~cm}(\mathrm{p}<0.01)$ and $33.3 \mathrm{~cm}(\mathrm{p}<0.01)$ respectively.

Conclusions: The lengths and head circumferences of babies born to working mothers were significantly more compared to those of babies born to non-working mothers but no difference was found with respect to birth weights.

DOI: http://dx.doi.org/10.4038/sljch.v45i4.8190

(Key words: Working women, newborn, growth parameters)

\section{Introduction}

In developing countries, an increase has been noted in the percentage of occupationally active women at reproductive age. The life style of a woman during pregnancy exerts a considerable effect on the course of pregnancy and the development of a fetus before and after birth. Majority of working women are worried about the effect of stress and duration of work on their pregnancy outcome. A study done on the effects of selected occupational factors on the

${ }_{1}$ Associate Professor, Department of Paediatrics,

${ }^{2}$ Assistant Professor Department of Obstetrics and Gynaecology, ${ }^{3}$ Medical Student, Sapthagiri Institute of Medical Sciences, Bangalore, Karnataka, India

*Correspondence: sunildoc.tmk@gmail.com

(Received on 04 February 2016: Accepted after revision on 17 March 2016)

The authors declare that there are no conflicts of interest

Personal funding was used for this project.

Open Access Article published under the Creative

Commons Attribution CC-BY cc) (i) newborn revealed that occupational activity in pregnancy causes an increase of pressure in the abdominal cavity, which may result in uterine contractions. A considerable part of the cardiac output is directed to the working group of muscles, contributing to decrease in blood flow in the internal organs, including the uterus and placental bed ${ }^{1,2}$.

\section{Objective}

To compare neonatal growth parameters in babies of working and non-working women.

\section{Method}

This is a hospital based comparative study conducted on pregnant women delivering in Sapthagiri Teaching Hospital. The study was conducted after ethical committee clearance. All pregnant women between 18-35 years of age and their newborns who were born in our hospital were included. Newborns with birth asphyxia, preterm and sick babies requiring neonatal intensive care unit (NICU) admission were excluded. Mothers suffering from medical conditions like heart disease and renal disease, mothers who had any uterine malformations, placenta praevia, short stature and other obstetric disorders were excluded.

A total of 68 subjects was selected during their antenatal visit to the hospital. Among them, 7 preterm deliveries were eliminated from the study. Thirty in the working group and 30 (1 eliminated to match) in the non-working group were evaluated. The study period was from $16^{\text {th }}$ May to $16^{\text {th }}$ July 2014. The respondents were informed about the use of information and oral consent was taken. The technique of collection of relevant data was by a self-designed questionnaire, where maternal age, education, socio-economic status, type of work, hours of work and family support were documented.

The birth weight was recorded within 24 hours after birth without any form of clothing using a digital paediatric weighing machine. The head circumference was recorded after completion of 72 hours by a measuring tape on the bony prominences of occiput and frontal bones (occipito-frontal circumference). The length of the baby was measured on the $3 \mathrm{rd}$ day using an infantometer. The data collected was subjected to statistical analysis and categorized using SPSS software version 16.0. Student-' $t$ ' test and Chi square test were used to see the statistical significance between the two groups. 
Results

Age wise and parity wise there was no statistical significance found between the groups. In the working mother group 6 were doing intellectual work and 24 mothers were doing light manual work during pregnancy. The minimum hours of work was 6 hours and maximum was 10 hours. Twenty-eight $(92 \%)$ mothers worked till 7- 9 months of gestation. In our study, there was no significant difference between the birth weights of babies born to working and non-working mothers. In working women the mean length of newborns was found to be $51.8 \mathrm{~cm}$, which was significantly more when compared to newborns of the non-working group $(p<0.01)$. In working women, the mean head circumference of newborns was $34.3 \mathrm{~cm}$, which was significantly more when compared to newborns of the nonworking group $(\mathrm{p}<0.01)$. [Table 1]

Table 1: Comparison of birth weight, length and head circumference

\begin{tabular}{|l|c|c|c|c|c|c|}
\hline \multirow{2}{*}{ Category } & \multicolumn{2}{|c|}{ Birth weight (kg) } & \multicolumn{2}{c|}{ Length (cm) } & \multicolumn{2}{c|}{ Head circumference (cm) } \\
\cline { 2 - 7 } & Mean & SD & Mean & SD & Mean & SD \\
\hline Non-working & 2.81 & 0.378 & 48.55 & 2.59 & 33.27 & 1.462 \\
\hline Working & 2.84 & 0.803 & 51.79 & 2.70 & 34.29 & 1.043 \\
\hline t-value & \multicolumn{2}{|c|}{1.020} & \multicolumn{2}{c|}{5.764} & \multicolumn{2}{c|}{3.14} \\
\hline Degree of differentiation & \multicolumn{2}{|c|}{59} & \multicolumn{2}{c|}{$<0.01$} & \multicolumn{2}{c|}{$<0.01$} \\
\hline p-value & \multicolumn{2}{|c|}{$>0.05$} & \multicolumn{2}{c}{} \\
\hline
\end{tabular}

The pregnancy complications have occurred equally in both working and non-working mothers. There was no change in the mode of delivery of working mothers when compared to non-working mothers $(\mathrm{p}>0.05)$. Regarding Apgar score of newborn, there is no association found between the non-working and working mothers at the first and fifth minute.

\section{Discussion}

Our study revealed that the length and head circumference of newborns born to working mothers were statistically greater when compared to newborns of non-working mothers and no difference was found with respect to birth weight. Torbizadeh A et al did a study to compare newborn anthropometry indices in housewives and employed women. The study concluded that the maternal job had a direct positive influence on their newborns' length and head circumference $(p<0.01, p<0.05$ respectively) whereas the weight was not significantly different $(\mathrm{p}>0.05)$ in the two groups ${ }^{3}$. A study by Makowiec DT et al. concluded that a slightly lower infant body mass was observed in those born to the mothers working for 9 hours a day and involving in hard physical work or working in the environment with harmful chemicals ${ }^{4}$. A study done by Zuckerman et al assessed the effects of paid work outside home during pregnancy particularly in the third trimester and showed no relationship between mother's work during pregnancy and their infant's anthropometry ${ }^{5}$. A study by Rao $\mathrm{S}$ et al to describe the relation of mother's physical activity to the birth size of her baby in rural Indian population, showed higher maternal activity in early as well as in mid gestation was associated with lower mean birth weight and a smaller neonatal head circumference $^{6}$. Studies by Birnacka JB et $a l^{7}$, Naeye RL et $a l^{8}$, Rabkin CS et $a l^{9}$ and Lin YC et $a l^{10}$ found a lower birth weight in newborns born to working group of mothers. According to the present study, women need not worry about going to work during their pregnancy, but studies in larger numbers are required to know the clear picture.

\section{Conclusions}

In our study, the length and head circumference of babies born to working mothers were significantly more compared to those of babies born to nonworking mothers.

\section{Acknowledgements}

We thank ICMR for approving and encouraging the project.

\section{References}

1. Wodowaik A, Stec M, Iwanowicz-Paius GJ, Mroczkowski A. Evaluation of effect of selected occupational factors on termination of pregnancy and state of the new born. Journal of Pre-Clinical and Clinical Research 2012; 6(2): 122-5.

2. Banerjee B. Physical hazards in employment and pregnancy outcome. Indian Journal of Community Medicine 2009; 34(2): 89-93.

http://dx.doi.org/10.4103/0970-

0218.51224

PMid: 19966951 PMCid: PMC2781135

3. Torabizadeh A, Esmaili H. Newborn body indices in housewives and working mothers. Journal of Family and Reproductive Health 2008; 2(2): 103-6.

4. Makoweic DT, Siedlecka J, Radwan WZ, Koszada WW, Wilczynski J. The effects of mother's occupation on body mass of newborns at term. Med Pr. 1977; 48(4): 381-92. 
5. Zukerman BH, Frank DA, Hingsonr R, Morelock S, Kayne HL. Effect of maternal work outside the home during pregnancy on neonatal outcome. Pediatrics 1986; 77(4): 459-64.

6. Rao S, Kanade A, Margetts BM, Yajnik CS, Lubree H, Rege S et al. Maternal activity in relation to birth size in rural India. The Pune Maternal Nutrition Study. European Journal of Clinical Nutrition 2003; 57: 531-42.

http://dx.doi.org/10.1038/sj.ejcn.1601582 PMid: 12700614

7. Biernacka JB, Hanke W. The effect of occupational and non-occupational psychosocial stress of pregnancy and its outcome. Med Pr. 2006; 57(3): 281-290.

PMid: 17125035
8. Naeye RL, Peters EC. Working during pregnancy: Effects on the fetus. Pediatrics 1982; 69 (6): 724-7.

PMid: 7079037

9. Rabkin CS, Anderson HR, Bland JM, Brooke OG, Chamberlain G, Peacock JL. Maternal activity and birth weight: A prospective population- based study. American Journal of Epidemiology 1990; 131(3): 522-31.

PMid: 2301361

10. Lin YC, Chen MH, Hsieh CJ, Chen PC. Effect of rotating shift work on child bearing and birth weight: A study of women working in a semiconductormanufacturing factory. World Journal of Pediatrics 2011; 7(2): 129-35. http://dx.doi.org/10.1007/s12519-0110265-9

PMid: 21574029 